\title{
Diabetes mellitus and bone health: epidemiology, etiology and implications for fracture risk stratification
}

\author{
Rodrigo J. Valderrábano* (1D and Maria I. Linares
}

\begin{abstract}
Skeletal fractures can result when there are co-morbid conditions that negatively impact bone strength. Fractures represent an important source of morbidity and mortality, especially in older populations. Diabetes mellitus is a metabolic disorder that has reached worldwide epidemic proportions and is increasingly being recognized as a risk factor for fracture. Type 1 and Type 2 diabetes have different effects on bone mineral density but share common pathways, which lead to bone fragility. In this review, we discuss the available data on diabetes and fractures, bone density and the clinical implications for fracture risk stratification in current practice.
\end{abstract}

Keywords: Diabetes mellitus, Type 1 diabetes mellitus, Type 2 diabetes mellitus, Bone mineral density, Fracture, Fracture risk stratification, Osteoporosis

\section{Background}

Osteoporosis is a systemic disease, which confers decreased bone strength and increased fracture risk [1-3]. Hip fractures especially are a major source of morbidity and mortality in older populations [4] and present an increasing public health burden [5]. Diabetes mellitus type 2 accounts for $90-95 \%$ of the incidence of diabetes $[6,7]$ and its prevalence is increasing worldwide [8]. Type 2 diabetes mellitus (T2DM) is associated with an increased bone mineral density (BMD) but a paradoxically increased risk for skeletal fractures [9-11]. Type 1 diabetes mellitus (T1DM) is less prevalent, but its incidence is rising, especially in the very young [12] and it has also been associated with increased fracture risk [13]. The causative mechanisms for this association are the subject of study by several groups but have not been completely elucidated. This article aims to evaluate the relationship of diabetes etiology, duration and glucose control with $\mathrm{BMD}$ and skeletal fracture. We also discuss potential strategies that increase the accuracy of fracture risk estimates in populations with diabetes mellitus, which could be applied to current clinical practice.

\footnotetext{
* Correspondence: rvalderrabano@med.miami.edu

University of Miami Miller School of Medicine, Dominion Tower 1400 NW 10th Ave, Ste. 805A, Miami, FL 33136, USA
}

Diabetes and fracture risk

Diabetes mellitus has been associated with increased fracture risk by several groups. The Nurses' Health Study followed 109,983 women aged 34-59 years old with biennial questionnaires for over 20 years and monitored the occurrence of hip fractures. They found that the risk of hip fracture in women with T1DM was sixfold higher compared with those without diabetes [14]. The Health Improvement Network (THIN) study used longitudinal electronic medical record data in the United Kingdom (UK) to evaluate incident fractures in men and women with T1DM from age 0 to 89 years old, across a median of 4.7 years of follow up. They found that the risk of incident fracture of any type increased in both sexes and in all age groups compared to those without diabetes. When stratified by age, women with T1DM ages 40-49 had the highest risk for fracture at any site, $82 \%$ higher than women without diabetes after multivariate adjustment. Men aged 60-69 with T1DM also had double the risk of fracture at any site compared to men without diabetes in the same age group [15]. The same study performed secondary analyses evaluating hip fracture specifically and found that men aged 60-69 with T1DM had $421 \%$ increased risk of hip fracture as compared to those without diabetes after adjustment for confounders. Young women with T1DM, in the

(c) The Author(s). 2018 Open Access This article is distributed under the terms of the Creative Commons Attribution 4.0 International License (http://creativecommons.org/licenses/by/4.0/), which permits unrestricted use, distribution, and 
30-39 years old group had a 316\% increase in the risk of hip fracture compared to those without, the highest magnitude increase in this sex. The authors concluded that fracture risk in T1DM is increased early on in life and that it is maintained throughout. The magnitude of fracture risk seemed to be higher in the lower extremity than at other sites. Others have also identified an association between T1DM and fractures. A cross-sectional case-control study of 82 young eastern European participants (mean age 31.1) with T1DM revealed a 320\% increased risk of asymptomatic vertebral fractures compared with controls which was independent of multiple covariates, including lumbar spine bone density [16]. Similarly, a large registry based cohort study from Taiwan age and sex matched 500,868 diabetic patients (identified by diagnosis codes) and found that men and women with diabetes had a $28 \%$ and $72 \%$ increased risk of hip fracture compared to controls without diabetes. When stratified by age this study revealed that the hazard ratios (HR) for hip fracture were higher for diabetic men and women aged 35 to 44 and were null statistically in men over 74 and women over 84 [17]. It may be that age or menopause related changes overshadow the effect of diabetes on fracture risk, which is why we see disparities between the young and old.

Several studies have found associations between T2DM and skeletal fractures. In the Women's Health Initiative observational cohort 93,676 generally healthy postmenopausal women were followed for 7 years. Women with T2DM at baseline had a $20 \%$ increased risk of fracture at any site after adjusting for multiple covariates, including frequency of falls [9]. The Study of Osteoporotic fractures followed 9654 women 65 years or older for an average of 9.4 years. Radiology reports were used to confirm reported incident fractures. They found that women diagnosed with diabetes after the age of 40 had a 30\% increased risk of having any non-vertebral fracture and an $82 \%$ increased hip fracture risk compared with those without diabetes. The risk of vertebral fracture was not significantly increased in this analysis [18]. Other studies have specifically evaluated vertebral fractures. A cross-sectional study from Japan ascertained fractures from spinal and thoracic radiographs in participants over 50 years old and found that men and women with T2DM had a $373 \%$ and $82 \%$ increased risk of having prevalent vertebral fractures respectively after adjustment for lumbar spine bone density [19]. In contrast, a cross-sectional evaluation of the Canadian Multicenter Osteoporosis study did not find that self-reported T1DM nor T2DM was associated with vertebral deformity determined by spinal radiographs among older men and women (mean age 66) [20]. One population-based study evaluated all reported fractures in Denmark and found that T2DM was associated with a $19 \%$ increased risk of any fracture while T1DM was associated with $30 \%$ increased risk. In this study T1DM was associated with a significantly increased risk of spine fracture while T2DM was not, in contrast both T1DM and T2DM were associated with increased risk for hip fracture when compared to age and sex matched controls [21].

Data from these large well executed studies across multiple populations consistently find that people with T1DM or T2DM have increased fracture risk. Findings for hip fractures seem to be more consistent than those for vertebral fractures, but may depend on the specific populations studied. T1DM may be associated with a lifelong increased risk of fracture. Two meta-analyses evaluating published case-control and cohort studies have found that hip fracture risk was significantly higher for T1DM than T2DM without overlapping confidence intervals [22, 23], suggesting the magnitude of fracture increase is higher in T1DM than in T2DM. It may be that there are different mechanisms of increased fragility for T1DM and T2DM or that disease duration and diabetes control have modulating effects. A summary of fracture risk by diabetes type is presented in Table 1 .

\section{Diabetes and bone density}

In T1DM, the association of bone mineral density with increased fracture risk is one of the most studied potential mechanisms. Bone density is decreased in T1DM. In a study of premenopausal women, those with T1DM had lower total hip (TH), femoral neck (FN) and whole body BMD after adjusting for multiple covariates, with no difference in lumbar spine (LS) BMD. The bone turnover markers osteocalcin and $\mathrm{N}$-telopeptides of type I collagen were evaluated but did not significantly change the diabetes-BMD association [24]. In one small European study men with T1DM (mean age 43) had similar TH BMD but significantly lower spine BMD $\mathrm{z}$ score than age matched controls ( $Z$ score -0.705 vs. -0.099) [25]. In the Fremantle diabetes study in Australia middle aged men with T1DM had significantly lower $\mathrm{TH}$ and FN BMD when compared to age and sex matched controls, but women with T1DM and matched controls had similar BMD at each site [26]. Multiple other studies have found lower BMD in T1DM, often associated with the presence of microvascular complications [24, 27-30]. The limited sample size in these individual studies preclude wide generalizations, however a systematic review and meta-analysis found that aggregate estimates of published studies showed significantly lower BMD at the spine ( $Z$ score $-0.22 \pm 0.01)$ and hip ( $Z$ score $-0.37 \pm 0.16$ ) in participants with T1DM compared with those without diabetes [22].

In children, low bone density for age may be present early after diagnosis of T1DM. A case control study evaluating children with recently diagnosed T1DM revealed significantly decreased LS BMD and decreased 
Table 1 Association of diabetes mellitus and fracture risk

\begin{tabular}{|c|c|c|c|c|}
\hline Type of diabetes & Fracture type & Findings & Study design & Reference \\
\hline Type 1 diabetes mellitus & Hip fracture & RR 7.10 (Cl 95\%: 4.4-11.4) & Prospective observational & Janghorbani et al. \\
\hline \multirow[t]{2}{*}{ Type 1 diabetes mellitus Men 60-69yo } & Any type & HR 2.00 (Cl 95\%: 1.63-2.45) & \multirow[t]{4}{*}{ Prospective observational } & \multirow[t]{4}{*}{ Weber et al. } \\
\hline & Hip fracture & HR 5.21 (Cl 95\%: 3.2-8.47) & & \\
\hline Type 1 diabetes mellitus Men 40-49yo & Any type & HR 1.82 (Cl 95\%: 1.53-11.43) & & \\
\hline Type 1 diabetes mellitus Men 30-39yo & Hip fracture & HR 4.16 (Cl 95\%: 1.52-11.43) & & \\
\hline Type 1 diabetes mellitus & Vertebral fracture & OR 4.20 (Cl 95\%: 1.40-12.7) & Cross sectional & Zhukouskaya et al. \\
\hline Type 1 diabetes mellitus men & Hip fracture & HR 1.28 (Cl 95\%: 1.21-1.34) & \multirow[t]{2}{*}{ Prospective observational } & \multirow[t]{2}{*}{ Chen et al. } \\
\hline Type 1 diabetes mellitus women & Hip fracture & HR 1.72 (Cl 95\%: 1.66-1.78) & & \\
\hline Type 1 diabetes mellitus & Hip fracture & RR 6.94 (Cl 95\%: 3.25-14.78) & \multirow[t]{2}{*}{ Meta-analysis observational studies } & \multirow[t]{2}{*}{ Vastergaard et al. } \\
\hline Type 2 diabetes mellitus & Hip fracture & RR 1.38 (Cl 95\%: 1.25-1.53) & & \\
\hline Type 2 diabetes mellitus & Any site & RR 1.20 (Cl 95\%: 1.11-1.30) & Prospective observational & Bonds et al. \\
\hline \multirow[t]{3}{*}{ Type 2 diabetes mellitus } & Non-vertebral & RR 1.30 (Cl 95\%: 1.10-1.53) & \multirow[t]{3}{*}{ Prospective observational } & \multirow[t]{3}{*}{ Schwartz et al. } \\
\hline & Hip fracture & RR 1.82 (Cl 95\%: 1.24-2.69) & & \\
\hline & Vertebral & RR 1.12 (Cl 95\%: 0.69-1.83) & & \\
\hline Type 2 diabetes mellitus Men & Vertebral & OR $4.73(\mathrm{Cl} 95 \% 2.19-10.20)$ & \multirow[t]{2}{*}{ Cross sectional } & \multirow[t]{2}{*}{ Yamamoto et al. } \\
\hline Type 2 diabetes mellitus Women & Vertebral & OR $1.86(\mathrm{Cl} 95 \% 1.11-3.12)$ & & \\
\hline Type 2 diabetes mellitus Men & Vertebral & OR 0.77 (Cl 95\% 0.48-1.22) & \multirow[t]{2}{*}{ Cross sectional } & \multirow[t]{2}{*}{ Hanley et al. } \\
\hline Type 2 diabetes mellitus Women & Vertebral & OR 0.92 (Cl 95\% 0.67-1.26) & & \\
\hline
\end{tabular}

bone formation markers when compared to age, height, and pubertal status matched controls [31]. This study also revealed that LS BMD was significantly lower in those with longer duration since T1DM diagnosis, indicating that diabetes may hamper acquisition of peak bone density during development. Similarly, a cross sectional study conducted in Caucasian children and adolescents with and without T1DM related complications found that duration of diabetes in years was negatively associated with both LS and total body BMD [32]. Bone turnover markers were negatively associated with hemoglobin A1C (HgbA1C) in this study, indicating a potential beneficial role of improved glucose control on bone growth. An additional case control study conducted on 86 younger participants (mean age 27.2) with T1DM, BMD at the total body and LS sites were significantly decreased compared to controls [33]. These findings must be interpreted with caution however, since children with chronic illnesses may have delayed puberty and therefore may not have the same bone size as controls, a factor which could lead to the appearance of significantly lower BMD [34].

In T2DM many studies have not found decreased BMD and some have shown paradoxically increased BMD. In the Women's Health Initiative women with T2DM had statistically significant increases in BMD at the spine and hip compared to women without diabetes throughout 9 years of follow up [9]. Other studies have shown increased BMD at the lumbar spine and hip in men and women with T2DM who were not using insulin [35], and increased BMD at the hip and forearm in women with T2DM [26]. One meta-analysis found that in T2DM a composite $\mathrm{Z}$ score was 0.41 higher at the spine and 0.27 at the hip than in non-diabetic controls. The same study performed a meta-regression analysis and found that BMI was a predictor of bone density in T2DM but not T1DM [22]. Increased BMI has well established associations with development of T2DM [36-39] and weight is also associated with increased bone density at weight bearing sites [40-42]. However some studies have shown that fracture risk in T2DM is independent of BMI or weight and height $[9,18]$, and $\operatorname{BMD}[18,19,43]$ which may indicate that the combined adverse effects of T2DM on bone may overwhelm any of the potential protective benefits from increased bone density.

One analysis of the osteoporotic fractures in men study evaluated volumetric bone mineral density (vBMD) and estimated bone strength using polar strength strain index and section modulus derived from peripheral quantitative computed tomography (pQCT). Older men with T2DM had bone strength that is low despite no difference in cortical vBMD [44], a finding that could imply that normal BMD should not be considered clinically reassuring in diabetes. Other studies have found that the presence of microvascular disease was associated with deficits in 
microarchitecture of bone, specifically of cortical and trabecular vBMD in T1DM [45] and cortical bone in T2DM [46], which may be driven by high cortical porosity [47]. These structural changes could partly explain the excess fracture risk in these populations.

T1DM and T2DM appear to interact differently with BMD. T1DM may contribute to low BMD, perhaps due to younger age at onset affecting growth of bone and peak bone mass. Increased weight and BMI, a common pathway for both increased BMD and development of T2DM may account for the increased BMD in T2DM. High BMD in T2DM is not entirely protective however, and bone strength may actually be lower than what is predicted for BMD. The microvascular changes of diabetes have been associated with microarchitectural bone defects, which may lead to bone fragility.

\section{Mechanisms for increased fracture risk in diabetes}

Shared mechanisms for increased fracture risk in both T1DM and T2DM include accumulation of advanced glycation end-products (AGEs) [48-51], chronic hyperglycemia, poor blood glucose control [43, 52], hypercalciuria [53] and high propensity for falls [54, 55]. AGEs are permanently deposited glyco-oxidation products whose formation is thought to be stimulated by intracellular hyperglycemia [56]. AGEs can form cross-links with proteins like collagen that affect their structure and functions [49]. A growing body of evidence indicates that AGEs play a crucial role in the progression of classical diabetes complications [57] and diabetic osteopathy. Collagen is a prominent component of bone and when AGEs such as pentosidine and carboxymethyl lysine are produced in collagen fibers, bone strength deteriorates [58-61], which is one potential explanation for why the increased fracture risk in T1DM and T2DM appears to be independent of BMD [51, 62, 63]. Elevated glucose levels accelerate AGE formation [64] and so diabetes control could be an important determinant of bone fragility. Hyperglycemia has direct effects on bone cells as well, inhibiting osteoclastogenesis [65].

Diabetes is associated with decreased bone turnover which could have deleterious effects on bone health. Rodent models of insulin deficiency can have decreased bone growth and turnover driven by decreased osteoblast recruitment. This phenotype can be partially corrected by administration of insulin like growth factor-1 (IGF-1) [66]. In T1DM and in the late stages of T2DM, insulin deficiency could impair bone homeostasis through dysregulation of the growth hormone-IGF-1 axis [53]. Pooled data has shown that bone formation markers such as osteocalcin, procollagen type 1 amino terminal pro-peptide and bone resorption markers such as C-terminal cross-linked telopeptide were significantly lower among those with diabetes and did not necessarily correlate with glucose level [67]. It has been suggested that diabetes mellitus should be considered a state of low bone turnover, perhaps driven by increased serum levels of sclerostin and osteoprotegerin which are known to inhibit osteoblast and osteoclast differentiation respectively [68].

The microvascular complications of diabetes mellitus have been associated with an increased propensity for falls, which could partially explain increases in skeletal fractures. In a cohort of well-functioning older adults, diabetes-related complications of reduced peripheral nerve function, poor vision, and decreased renal function were all associated with increased risk of falls. The study further suggested that even a modest decline of renal function could account for increased fall risk through lower muscle strength and nerve function from lower levels of active vitamin D [54]. The Study of Osteoporotic Fractures revealed an increased risk of falls in women with diabetes, especially in those treated with insulin, who had more than double the risk of having multiple falls than women without diabetes [55] . Poor balance and peripheral neuropathy were found to be important risk factors associated with falls in this study.

\section{Glucose control, length of disease and fracture risk}

Given the potential mechanisms described above one would expect that the higher glucose levels from poor diabetes control and longer exposure to diabetes may result in increased fracture risk. This principle has been borne out in several studies. The Action to Control Cardiovascular Risk in Diabetes (ACCORD) trial randomized participants with T2DM to intensive or standard glycemic control strategies. Those in the intensive glycemia group achieved a median HgbA1C of $6.4 \%$ as compared to $7.5 \%$ in the standard glycemia group. They found that intensive glycemic control was not significantly associated with fracture or fall risk compared with standard therapy [69]. In the Health in Aging and Body Composition prospective cohort study adults 70-79 years old with T2DM (HgbA1C > 7\%) were found to have a $64 \%$ increased risk of incident clinical fractures while those with Impaired Fasting Glucose, an intermediate state of abnormal glucose metabolism between normal glucose homeostasis and diabetes, did not have significantly increased risk. In this study participants with T2DM had reduced peripheral sensation, lower lean mass, more falls and lower total hip bone density, highlighting diabetic complications as important considerations in the elderly individuals with T2DM [70]. A community-based prospective cohort study stratified participants with known diabetes by HgbA1C level and compared the risk of hospitalization due to fracture across a median follow up of 20 years. Participants with HgbA1c $\geq 8 \%$ had a $63 \%$ higher risk of hospitalization due to fracture compared 
with those whose HgbA1C was under 8\% [71]. Those with unrecognized diabetes prior to study initiation and pre-diabetes did not have increased hospitalization risk compared to those with HgbA1C under 5.7\%. Similarly, a prospective population-based cohort in the Netherlands determined that patients with $\mathrm{T} 2 \mathrm{DM}$ and $\mathrm{HgbA1C}$ over 7.5\% had a $62 \%$ increased risk of all types of fractures compared to those with HgbA1C under 7.5\% after adjustment for covariates including FN BMD [43]. In the United States (US) NHANES database those with diagnosed diabetes or HgbA1C above $6.5 \%$ had a significantly increased risk of non-skull fractures compared to non-diabetes controls but those with pre-diabetes did not have a significantly increased fracture risk [72]. Epidemiological data from the National Diabetes Care Program in Taiwan revealed that among 20,025 patients with T2DM aged 65 years or older the risk of hip fracture appeared to increase in a dose-response relationship with each $1 \% \mathrm{HgbA1C}$ increase above $8 \%$, compared to those with $\mathrm{HgbA1C}$ of $6-7 \%$. The increased hip fracture risk was maintained after adjustment for co-variates among patients with $\mathrm{HgbA1C}$ levels in the 9-10\% range and those with $\mathrm{HgbA1C}$ above $10 \%$, suggesting that fracture risk may be increased commensurate to the magnitude of poor glucose control [52]. Similar findings were noted in patients with T1DM in the THIN study where each $1 \%$ greater average $\mathrm{HgbA1C}$ level was associated with a 5\% greater risk of incident fractures in males and $11 \%$ greater risk in females [15]. In this study, diabetic neuropathy and retinopathy were found to be risk factors for fracture in males but only diabetic neuropathy was significant in females.

Longer duration of diabetes appears to increase fracture risk as well. In the Nurses' Health study there was a significant trend for greater fracture risk with increased duration of diabetes. Fracture risk was increased by $200 \%$ with diabetes duration over 12 years [14]. In a cohort of 82,094 diabetic adults in Manitoba, Canada diabetes duration of over 5 years increased the risk of combined hip, wrist and spine fractures compared to age and sex matched controls. Interestingly, newly diagnosed diabetes was found to significantly reduce the risk of fracture in this cohort [73]. In a prospective study of the residents of Blue Mountains in Australia diabetes duration over 10 years was also significantly associated with all fractures [74].

Poor glucose control and longer exposure to hyperglycemia are known to lead to increased AGEs and the development of the microvascular complications of diabetes including retinopathy, neuropathy and nephropathy $[56,75,76]$ which have been associated with microarchitectural changes in bone as previously discussed. These mechanisms may be leading to bone fragility. More data from large prospective cohorts are needed to evaluate the direct effects of microvascular complications on fracture risk. It seems that fracture risk is lower in patients with $\mathrm{HgbA1C}$ under $7.5 \%$ and may increase as HgbA1C climbs over $8 \%$. However, it appears that improvement beyond reasonable control (HgbA1C around 7.5\%) may not lead to additional benefit. While initially T2DM may be protective for fracture, possibly due to hyperinsulinemia through insulin's homology with IGF-1 causing increased bone strength [53, 77], longer exposure of diabetes is associated with increased fracture risk.

\section{Glucose-lowering medications and fracture risk}

Medications used to treat diabetes mellitus can modulate fracture risk. Treatment with thiazolidinediones increased risk of fractures in women with T2DM independent of age and duration of exposure $[78,79]$. Thiazolidinediones activate peroxisome proliferator-activated receptors (PPARs) which are factors that promote adipogenesis. Mesenchymal stem cells (MSC) are the common precursors of adipocytes and osteoblasts and PPARy is an important regulator of MSC differentiation [80]. The increased fracture risk with thiazolidinediones could be due to activation of PPARy shifting differentiation of MSCs towards adipogenesis and away from osteogenesis through the suppression of key osteogenic transcription factors. Insulin and sulfonylurea use has also been associated with increased fracture risk $[81,82]$ a finding which could be partially explained by the higher incidence of hypoglycemic events and risk of falls $[54,82]$. Metformin has been shown to have a positive or neutral effect on BMD and fracture risk [21]. Sodium glucose co-transporter-2 (SGLT-2) inhibitors such as dapaglifozin did not impact bone turnover markers or BMD [83]. Canaglifozin has been associated with bone loss and increased fracture risk at the hip [84]. More studies are needed to clarify the SGLT-2 class effect on bone fracture risk. Clinical evidence is lacking for dipeptidyl peptidase-4 inhibitors and glucagon like peptide-1 analogs [85].

\section{Fracture risk stratification for diabetes}

FRAX is a useful but imperfect tool for fracture risk stratification [86]. Osteoporosis guidelines in the US and UK recommend its use in treatment algorithms [2, 87, 88]. FRAX has been shown to underestimate major osteoporotic fracture and hip fracture risk in patients with diabetes $[10,89]$. The University of Manitoba group has made great contributions in determining the effects of diabetes on fracture risk stratification with FRAX. They have shown that the effect of diabetes is independent of other FRAX risk factors, but appears to be more important for hip fracture prediction in younger individuals [90]. Duration of diabetes was associated with hip fracture independent of FRAX scores in a dose dependent fashion, but was associated with increased major osteoporotic fracture risk only at 10 years duration [91]. One strategy to modify FRAX scores to more 
accurately reflect the estimated fracture risk in diabetes is to include rheumatoid arthritis as a proxy for diabetes since they have similar effects on the FRAX algorithm [92]. Trabecular bone score (TBS) is a technology that when applied to bone density by DXA in the lumbar spine, predicts fractures [93] and identifies a greater proportion of those at risk than BMD in T2DM [94]. TBS can be used with FRAX to improve fracture prediction [95] and may be useful in T2DM, but is not commonly available in many clinical practices.

\section{Conclusions}

Type 1 and Type 2 diabetes mellitus both increase the risk of skeletal fracture, particularly at the hip. The etiology of diabetes determines its effects on BMD. Type 1 diabetes is associated with BMD decrease while T2DM is associated with normal to increased BMD. T1DM and T2DM have common mechanisms such as AGEs deposition and bone microarchitectural defects where cortical bone appears to be particularly affected. The increased fracture risk in DM is independent of FRAX and must be considered when risk stratifying patients in clinical practice. Diabetes mellitus should be considered an important fracture risk factor.

\section{Abbreviations}

AGEs: Advanced glycation end products; BMD: Bone mineral density; FN: Femoral neck; HgbA1C: Hemoglobin A1C; HR: Hazard ratio; IGF-1: Insulin like growth factor-1; LS: Lumbar spine; PPAR: Peroxisome proliferatoractivated receptors; SGLT-2: Sodium glucose co-transporter-2; T1DM: Type 1 diabetes mellitus; T2DM: Type 2 diabetes mellitus; TH: Total hip; THIN: The Health Improvement Network; vBMD: Volumetric bone mineral density; MSC: Mesenchymal stem cells; TBS: Trabecular bone score; US: United States; UK: United Kingdom

\section{Authors' contributions}

Conception and design of the article: RJV. Drafted the manuscript: RJV, MIL. Revised it critically for important intellectual content: RJV. Final approval of the version to be published: RJV, MIL.

\section{Ethics approval and consent to participate}

Not applicable.

\section{Competing interests}

The authors have no financial or non-financial competing interests to report.

\section{Publisher's Note}

Springer Nature remains neutral with regard to jurisdictional claims in published maps and institutional affiliations.

Received: 3 January 2018 Accepted: 9 April 2018

Published online: 25 April 2018

\section{References}

1. Dawson-Hughes B, Committee NOFG. A revised clinician's guide to the prevention and treatment of osteoporosis. The Journal of Clinical Endocrinology \& Metabolism. 2008;93(7):2463-5.

2. Compston J, Cooper A, Cooper C, Francis R, Kanis JA, Marsh D, McCloskey EV, Reid DM, Selby P, Wilkins M, et al. Guidelines for the diagnosis and management of osteoporosis in postmenopausal women and men from the age of 50 years in the UK. Maturitas. 2009;62(2):105-8.

3. Adler RA. Osteoporosis in men: a review. Bone Res. 2014;2:14001.
4. Kiebzak GM, Beinart GA, Perser K, Ambrose CG, Siff SJ, Heggeness MH. Undertreatment of osteoporosis in men with hip fracture. Arch Intern Med. 2002;162(19):2217-22.

5. Burge $\mathrm{R}$, Dawson-Hughes B, Solomon DH, Wong JB, King A, Tosteson A. Incidence and economic burden of osteoporosis-related fractures in the United States, 2005-2025. J Bone Miner Res. 2007;22(3):465-75.

6. Zimmet P, Alberti K, Shaw J. Global and societal implications of the diabetes epidemic. Nature. 2001;414(6865):782-7.

7. Cheng D. Prevalence, predisposition and prevention of type II diabetes. Nutrition \& metabolism. 2005:2(1):29.

8. Chen L, Magliano DJ, Zimmet PZ. The worldwide epidemiology of type 2 diabetes mellitus - present and future perspectives. Nat Rev Endocrinol. 2012;8(4):228-36.

9. Bonds DE, Larson JC, Schwartz AV, Strotmeyer ES, Robbins J, Rodriguez BL, Johnson KC, Margolis KL. Risk of fracture in women with type 2 diabetes: the Women's health initiative observational study. The Journal of clinical endocrinology \& metabolism. 2006;91(9):3404-10.

10. Schwartz AV, Vittinghoff E, Bauer DC, Hillier TA, Strotmeyer ES, Ensrud KE, Donaldson MG, Cauley JA, Harris TB, Koster A. Association of BMD and FRAX score with risk of fracture in older adults with type 2 diabetes. JAMA. 2011; 305(21):2184-92.

11. De Liefde I, Van der Klift M, De Laet C, Van Daele P, Hofman A, Pols H. Bone mineral density and fracture risk in type-2 diabetes mellitus: the Rotterdam study. Osteoporos Int. 2005;16(12):1713-20.

12. Patterson CC, Dahlquist GG, Gyürüs E, Green A, Soltész G, Group ES. Incidence trends for childhood type 1 diabetes in Europe during 1989-2003 and predicted new cases 2005-20: a multicentre prospective registration study. Lancet. 2009;373(9680):2027-33.

13. Miao J, Brismar K, Nyrén O, Ugarph-Morawski A, Ye W. Elevated hip fracture risk in type 1 diabetic patients. Diabetes Care. 2005;28(12):2850-5.

14. Janghorbani M, Feskanich D, Willett WC, Hu F. Prospective study of diabetes and risk of hip fracture. Diabetes Care. 2006;29(7):1573-8.

15. Weber DR, Haynes K, Leonard MB, Willi SM, Denburg MR. Type 1 diabetes is associated with an increased risk of fracture across the life span: a population-based cohort study using the health improvement network (THIN). Diabetes Care. 2015;38(10):1913-20.

16. Zhukouskaya W, Eller-Vainicher C, Vadzianava W, Shepelkevich AP, Zhurava IV, Korolenko GG, Salko OB, Cairoli E, Beck-Peccoz P, Chiodini I. Prevalence of morphometric vertebral fractures in patients with type 1 diabetes. Diabetes Care. 2013;36(6):1635-40.

17. Chen H-F, Ho C-A, Li C-Y. Increased risks of hip fracture in diabetic patients of Taiwan. Diabetes Care. 2008;31(1):75-80.

18. Schwartz AV, Sellmeyer DE, Ensrud KE, Cauley JA, Tabor HK, Schreiner PJ, Jamal SA, Black DM, Cummings SR. Older women with diabetes have an increased risk of fracture: a prospective study. The Journal of clinical endocrinology \& metabolism. 2001;86(1):32-8.

19. Yamamoto M, Yamaguchi T, Yamauchi M, Kaji H, Sugimoto T. Diabetic patients have an increased risk of vertebral fractures independent of BMD or diabetic complications. J Bone Miner Res. 2009;24(4):702-9.

20. Hanley D, Brown J, Tenenhouse A, Olszynski W, loannidis G, Berger C, Prior J, Pickard L, Murray T, Anastassiades T. Associations among disease conditions, bone mineral density, and prevalent vertebral deformities in men and women 50 years of age and older: cross-sectional results from the Canadian multicentre osteoporosis study. J Bone Miner Res. 2003;18(4):784-90.

21. Vestergaard $P$, Rejnmark $L$, Mosekilde $L$. Relative fracture risk in patients with diabetes mellitus, and the impact of insulin and oral antidiabetic medication on relative fracture risk. Diabetologia. 2005;48(7):1292-9.

22. Vestergaard $\mathrm{P}$. Discrepancies in bone mineral density and fracture risk in patients with type 1 and type 2 diabetes - a meta-analysis. Osteoporos Int. 2007;18(4):427-44.

23. Janghorbani M, Van Dam RM, Willett WC, Hu FB. Systematic review of type 1 and type 2 diabetes mellitus and risk of fracture. Am J Epidemiol. 2007; 166(5):495-505.

24. Strotmeyer ES, Cauley JA, Orchard TJ, Steenkiste AR, Dorman JS. Middleaged premenopausal women with type 1 diabetes have lower bone mineral density and calcaneal quantitative ultrasound than nondiabetic women. Diabetes Care. 2006;29(2):306-11.

25. Miazgowski T, Pynka S, Noworyta-Ziętara M, Krzyzanowska-Świniarska B, Pikul R. Bone mineral density and hip structural analysis in type 1 diabetic men. Eur J Endocrinol. 2007;156(1):123-7. 
26. Rakic V, Davis W, Chubb S, Islam F, Prince R, Davis T. Bone mineral density and its determinants in diabetes: the Fremantle diabetes study. Diabetologia. 2006;49(5):863.

27. Kayath MJ, Dib SA, Vieira JH. Prevalence and magnitude of osteopenia associated with insulin-dependent diabetes mellitus. J Diabetes Complicat. 1994;8(2):97-104.

28. Rix M, Andreassen H, Eskildsen P. Impact of peripheral neuropathy on bone density in patients with type 1 diabetes. Diabetes Care. 1999;22(5):827-31.

29. Clausen P, Feldt-Rasmussen B, Jacobsen P, Rossing K, Parving HH, Nielsen $P$, Feldt-Rasmussen $U$, Olgaard K. Microalbuminuria as an early indicator of osteopenia in male insulin-dependent diabetic patients. Diabet Med. 1997; 14(12):1038-43.

30. Eller-Vainicher C, Zhukouskaya W, Tolkachev YV, Koritko SS, Cairoli E, Grossi E, Beck-Peccoz P, Chiodini I, Shepelkevich AP. Low bone mineral density and its predictors in type 1 diabetic patients evaluated by the classic statistics and artificial neural network analysis. Diabetes Care. 2011;34(10):2186-91.

31. Gunczler P, Lanes R, Paoli M, Martinis R, Villaroel O, Weisinger J. Decreased bone mineral density and bone formation markers shortly after diagnosis of clinical type 1 diabetes mellitus. J Pediatr Endocrinol Metab. 2001;14(5):525-8.

32. Tsentidis C, Gourgiotis D, Kossiva L, Doulgeraki A, Marmarinos A, Galli-Tsinopoulou A, Karavanaki K. Higher levels of s-RANKL and osteoprotegerin in children and adolescents with type 1 diabetes mellitus may indicate increased osteoclast signaling and predisposition to lower bone mass: a multivariate cross-sectional analysis. Osteoporos Int. 2016;27(4):1631-43.

33. Bhagwat N. A study of bone mineral density and its determinants in type 1 diabetes mellitus. J Osteoporos. 2013;

34. Bachrach LK, Sills IN. Bone densitometry in children and adolescents. Pediatrics. 2011;127(1):189-94.

35. van Daele PL, Stolk RP, Burger H, Algra D, Grobbee DE, Hofman A, Birkenhager JC, Pols HA. Bone density in non-insulin-dependent diabetes mellitus: the Rotterdam study. Ann Intern Med. 1995:122(6):409-14.

36. Narayan KV, Boyle JP, Thompson TJ, Gregg EW, Williamson DF. Effect of BMI on lifetime risk for diabetes in the US. Diabetes Care. 2007;30(6):1562-6.

37. Kodama S, Horikawa C, Fujihara K, Heianza Y, Hirasawa R, Yachi Y, Sugawara A, Tanaka S, Shimano H, lida KT. Comparisons of the strength of associations with future type 2 diabetes risk among anthropometric obesity indicators, including waist-to-height ratio: a meta-analysis. Am J Epidemiol. 2012;176(11):959-69.

38. Ganz ML, Wintfeld N, Li Q, Alas V, Langer J, Hammer M. The association of body mass index with the risk of type 2 diabetes: a case-control study nested in an electronic health records system in the United States. Diabetology \& metabolic syndrome. 2014;6(1):50.

39. Schienkiewitz A, Schulze MB, Hoffmann K, Kroke A, Boeing H. Body mass index history and risk of type 2 diabetes: results from the European prospective investigation into Cancer and nutrition (EPIC)-Potsdam study. Am J Clin Nutr. 2006;84(2):427-33.

40. Felson DT, Zhang Y, Hannan MT, Anderson JJ. Effects of weight and body mass index on bone mineral density in men and women: the Framingham study. J Bone Miner Res. 1993;8(5):567-73.

41. Edelstein SL, Barrett-Connor E. Relation between body size and bone mineral density in elderly men and women. Am J Epidemiol. 1993;138(3):160-9.

42. Morin S, Tsang J, Leslie W. Weight and body mass index predict bone mineral density and fractures in women aged 40 to 59 years. Osteoporos Int. 2009;20(3):363-70.

43. Oei L, Zillikens MC, Dehghan A, Buitendijk GH, Castaño-Betancourt MC, Estrada K, Stolk L, Oei EH, van Meurs JB, Janssen JA. High bone mineral density and fracture risk in type 2 diabetes as skeletal complications of inadequate glucose control. Diabetes Care. 2013;36(6):1619-28.

44. Petit MA, Paudel ML, Taylor BC, Hughes JM, Strotmeyer ES, Schwartz AV, Cauley JA, Zmuda JM, Hoffman AR, Ensrud KE. Bone mass and strength in older men with type 2 diabetes: the osteoporotic fractures in men study. J Bone Miner Res. 2010;25(2):285-91.

45. Shanbhogue W, Hansen S, Frost M, Jorgensen NR, Hermann AP, Henriksen JE, Brixen K. Bone geometry, volumetric density, microarchitecture, and estimated bone strength assessed by HR-pQCT in adult patients with type 1 diabetes mellitus. J Bone Miner Res. 2015;30(12):2188-99.

46. Burghardt AJ, Issever AS, Schwartz AV, Davis KA, Masharani U, Majumdar S, Link TM. High-resolution peripheral quantitative computed tomographic imaging of cortical and trabecular bone microarchitecture in patients with type 2 diabetes mellitus. The Journal of Clinical Endocrinology \& Metabolism. 2010;95(11):5045-55.
47. Shanbhogue W, Hansen S, Frost M, Jørgensen NR, Hermann AP, Henriksen JE, Brixen K. Compromised cortical bone compartment in type 2 diabetes mellitus patients with microvascular disease. Eur J Endocrinol. 2016;174(2):115-24.

48. Paul R, Bailey A. Glycation of collagen: the basis of its central role in the late complications of ageing and diabetes. Int J Biochem Cell Biol. 1996;28(12): 1297-310.

49. Bos DC, de Ranitz-Greven WL, de Valk HW. Advanced glycation end products, measured as skin autofluorescence and diabetes complications: a systematic review. Diabetes Technol Ther. 2011;13(7):773-9.

50. Furst JR, Bandeira LC, Fan W-W, Agarwal S, Nishiyama KK, McMahon DJ, Dworakowski E, Jiang H, Silverberg SJ, Rubin MR. Advanced glycation endproducts and bone material strength in type 2 diabetes. The Journal of Clinical Endocrinology \& Metabolism. 2016;101(6):2502-10.

51. Neumann T, Lodes S, Kästner B, Franke S, Kiehntopf M, Lehmann T, Müller $U$, Wolf $G$, Sämann A. High serum pentosidine but not esRAGE is associated with prevalent fractures in type 1 diabetes independent of bone mineral density and glycaemic control. Osteoporos Int. 2014;25(5):1527-33.

52. Li Cl, Liu CS, Lin WY, Meng NH, Chen CC, Yang SY, Chen HJ, Lin CC, Li TC. Glycated hemoglobin level and risk of hip fracture in older people with type 2 diabetes: a competing risk analysis of Taiwan diabetes cohort study. J Bone Miner Res. 2015;30(7):1338-46.

53. Thrailkill KM, Lumpkin CK, Bunn RC, Kemp SF, Fowlkes $\mathrm{J}$. Is insulin an anabolic agent in bone? Dissecting the diabetic bone for clues. American journal of physiology-endocrinology and metabolism. 2005; 289(5):E735-45

54. Schwartz AV, Vittinghoff E, Sellmeyer DE, Feingold KR, De Rekeneire N, Strotmeyer ES, Shorr RI, Vinik Al, Odden MC, Park SW. Diabetes-related complications, glycemic control, and falls in older adults. Diabetes Care. 2008;31(3):391-6.

55. Schwartz AV, Hillier TA, Sellmeyer DE, Resnick HE, Gregg E, Ensrud KE, Schreiner PJ, Margolis KL, Cauley JA, Nevitt MC. Older women with diabetes have a higher risk of falls. Diabetes Care. 2002;25(10):1749-54.

56. Brownlee M. Biochemistry and molecular cell biology of diabetic complications. Nature. 2001;414(6865):813-20.

57. Goh S-Y, Cooper ME. The role of advanced glycation end products in progression and complications of diabetes. The Journal of Clinical Endocrinology \& Metabolism. 2008;93(4):1143-52.

58. Karim L, Vashishth D. Heterogeneous glycation of cancellous bone and its association with bone quality and fragility. PLoS One. 2012;7(4):e35047.

59. Hernandez CJ, Tang SY, Baumbach BM, Hwu PB, Sakkee AN, van der Ham F, DeGroot J, Bank RA, Keaveny TM. Trabecular microfracture and the influence of pyridinium and non-enzymatic glycation-mediated collagen cross-links. Bone. 2005;37(6):825-32.

60. Saito M, Fujii K, Marumo K. Degree of mineralization-related collagen crosslinking in the femoral neck cancellous bone in cases of hip fracture and controls. Calcif Tissue Int. 2006;79(3):160-8.

61. Yamamoto M, Yamaguchi T, Yamauchi M, Yano S, Sugimoto T. Serum pentosidine levels are positively associated with the presence of vertebral fractures in postmenopausal women with type 2 diabetes. The Journal of Clinical Endocrinology \& Metabolism. 2008;93(3):1013-9.

62. Yamamoto M, Yamaguchi T, Yamauchi M, Sugimoto T. Low serum level of the endogenous secretory receptor for advanced glycation end products (esRAGE) is a risk factor for prevalent vertebral fractures independent of bone mineral density in patients with type 2 diabetes. Diabetes Care. 2009; 32(12):2263-8.

63. Schwartz AV, Garnero P, Hillier TA, Sellmeyer DE, Strotmeyer ES, Feingold KR, Resnick HE, Tylavsky FA, Black DM, Cummings SR. Pentosidine and increased fracture risk in older adults with type 2 diabetes. The Journal of Clinical Endocrinology \& Metabolism. 2009;94(7):2380-6.

64. Yan SF, Ramasamy R, Schmidt AM. Mechanisms of disease: advanced glycation end-products and their receptor in inflammation and diabetes complications. Nat Rev Endocrinol. 2008:4(5):285-93.

65. Wittrant $Y$, Gorin Y, Woodruff K, Horn D, Abboud H, Mohan S, Abboud-Werner S. High d (+) glucose concentration inhibits RANKL-induced osteoclastogenesis. Bone. 2008;42(6):1122-30.

66. Verhaeghe J, Suiker A, Visser W, Van Herck E, Van Bree R, Bouillon R. The effects of systemic insulin, insulin-like growth factor-I and growth hormone on bone growth and turnover in spontaneously diabetic BB rats. J Endocrinol. 1992;134(3):485-92.

67. Starup-Linde J, Eriksen S, Lykkeboe S, Handberg A, Vestergaard P. Biochemical markers of bone turnover in diabetes patients-a 
meta-analysis, and a methodological study on the effects of glucose on bone markers. Osteoporos Int. 2014;25(6):1697-708.

68. Hygum K, Starup-Linde J, Harsløf T, Vestergaard P, Langdahl BL. Mechanisms in endocrinology: diabetes mellitus, a state of low bone turnover-a systematic review and meta-analysis. Eur J Endocrinol. 2017; 176(3):R137-57.

69. Schwartz AV, Margolis KL, Sellmeyer DE, Vittinghoff E, Ambrosius WT, Bonds DE, Josse RG, Schnall AM, Simmons DL, Hue TF. Intensive glycemic control is not associated with fractures or falls in the ACCORD randomized trial. Diabetes Care 2012;35(7):1525-31.

70. Strotmeyer ES, Cauley JA, Schwartz AV, Nevitt MC, Resnick HE, Bauer DC, Tylavsky FA, de Rekeneire N, Harris TB, Newman AB. Nontraumatic fracture risk with diabetes mellitus and impaired fasting glucose in older white and black adults: the health, aging, and body composition study. Arch Intern Med. 2005;165(14):1612-7.

71. Schneider AL, Williams EK, Brancati FL, Blecker S, Coresh J, Selvin E. Diabetes and risk of fracture-related hospitalization. Diabetes Care. 2013;36(5):1153-8.

72. Looker AC, Eberhardt MS, Saydah SH. Diabetes and fracture risk in older US adults. Bone. 2016:82:9-15.

73. Leslie WD, Lix LM, Prior HJ, Derksen S, Metge C, O'Neil J. Biphasic fracture risk in diabetes: a population-based study. Bone. 2007:40(6):1595-601.

74. Ivers RQ, Cumming RG, Mitchell P, Peduto AJ. Diabetes and risk of fracture. Diabetes Care. 2001;24(7):1198-203.

75. Fowler MJ. Microvascular and macrovascular complications of diabetes. Clinical diabetes. 2008;26(2):77-82.

76. Forbes JM, Cooper ME. Mechanisms of diabetic complications. Physiol Rev. 2013:93(1):137-88

77. Fukunaga Y, Minamikawa J, Inoue D, Koshiyama H. Does insulin use increase bone mineral density in patients with non-insulin-dependent diabetes mellitus? Arch Intern Med. 1997:157(22):2668-9.

78. Zhu Z-N, Jiang Y-F, Ding T. Risk of fracture with thiazolidinediones: an updated meta-analysis of randomized clinical trials. Bone. 2014;68:115-23.

79. Loke YK, Singh S, Furberg CD. Long-term use of thiazolidinediones and fractures in type 2 diabetes: a meta-analysis. Can Med Assoc J. 2009; 180(1):32-9.

80. Kawai M, Rosen CJ. PPARY: a circadian transcription factor in adipogenesis and osteogenesis. Nat Rev Endocrinol. 2010;6(11):629.

81. Monami M, Cresci B, Colombini A, Pala L, Balzi D, Gori F, Chiasserini V, Marchionni N, Rotella CM, Mannucci E. Bone fractures and hypoglycemic treatment in type 2 diabetic patients. Diabetes Care. 2008;31(2):199-203.

82. Lapane KL, Yang S, Brown MJ, Jawahar R, Pagliasotti C, Rajpathak S. Sulfonylureas and risk of falls and fractures: a systematic review. Drugs Aging. 2013;30(7):527-47.

83. Ljunggren Ö, Bolinder J, Johansson L, Wilding J, Langkilde A, Sjöström C, Sugg J, Parikh S. Dapagliflozin has no effect on markers of bone formation and resorption or bone mineral density in patients with inadequately controlled type 2 diabetes mellitus on metformin. Diabetes Obes Metab. 2012;14(11):990-9.

84. Watts NB, Bilezikian JP, Usiskin K, Edwards R, Desai M, Law G, Meininger G. Effects of canagliflozin on fracture risk in patients with type 2 diabetes mellitus. J Clin Endocrinol. 2016;101(1):157-66.

85. Mosenzon O, Wei C, Davidson J, Scirica BM, Yanuv I, Rozenberg A, Hirshberg B, Cahn A, Stahre C, Strojek K. Incidence of fractures in patients with type 2 diabetes in the SAVOR-TIMI 53 trial. Diabetes Care. 2015;38(11):2142-50.

86. Kanis JA, Hans D, Cooper C, Baim S, Bilezikian JP, Binkley N, Cauley JA, Compston JE, Dawson-Hughes B, Fuleihan GE-H. Interpretation and use of FRAX in clinical practice. Osteoporos Int. 2011;22(9):2395.

87. Dawson-Hughes B, Tosteson A. Melton Lr, Baim S, Favus M, Khosla S, Lindsay R: implications of absolute fracture risk assessment for osteoporosis practice guidelines in the USA. Osteoporos Int. 2008;19(4):449-58.

88. Cosman F, De Beur S, LeBoff M, Lewiecki E, Tanner B, Randall S, Lindsay R. Clinician's guide to prevention and treatment of osteoporosis. Osteoporos Int. 2014;25(10):2359-81.

89. Giangregorio LM, Leslie WD, Lix LM, Johansson H, Oden A, McCloskey E, Kanis JA. FRAX underestimates fracture risk in patients with diabetes. J Bone Miner Res. 2012;27(2):301-8.

90. Leslie W, Morin S, Lix L, Majumdar S. Does diabetes modify the effect of FRAX risk factors for predicting major osteoporotic and hip fracture? Osteoporos Int. 2014;25(12):2817-24.

91. Majumdar SR, Leslie WD, Lix LM, Morin SN, Johansson H, Oden A, McCloskey EV, Kanis JA. Longer duration of diabetes strongly impacts fracture risk assessment: the Manitoba BMD cohort. The Journal of Clinical Endocrinology \& Metabolism. 2016;101(11):4489-96.

92. Schacter Gl, Leslie WD. DXA-based measurements in diabetes: can they predict fracture risk? Calcif Tissue Int. 2017:100(2):150-64.

93. Hans D, Goertzen AL, Krieg MA, Leslie WD. Bone microarchitecture assessed by TBS predicts osteoporotic fractures independent of bone density: the Manitoba study. J Bone Miner Res. 2011;26(11):2762-9.

94. Leslie WD, Aubry-Rozier B, Lamy O, Hans D. TBS (trabecular bone score) and diabetes-related fracture risk. The Journal of Clinical Endocrinology \& Metabolism. 2013;98(2):602-9.

95. McCloskey EV, Odén A, Harvey NC, Leslie WD, Hans D, Johansson H, Barkmann R, Boutroy S, Brown J, Chapurlat R. A meta-analysis of trabecular bone score in fracture risk prediction and its relationship to FRAX. J Bone Miner Res. 2016;31(5):940-8.

\section{Ready to submit your research? Choose BMC and benefit from:}

- fast, convenient online submission

- thorough peer review by experienced researchers in your field

- rapid publication on acceptance

- support for research data, including large and complex data types

- gold Open Access which fosters wider collaboration and increased citations

- maximum visibility for your research: over $100 \mathrm{M}$ website views per year

At BMC, research is always in progress.

Learn more biomedcentral.com/submissions 